\title{
Flue gas moisture capacity calculation at the outlet of the condensation heat recovery unit
}

\author{
Nikolay Galashov ${ }^{1, *}$, Svyatoslav Tsibulskiy ${ }^{1}$, Denis Mel'nikov ${ }^{1}$, Alexandr Kiselev ${ }^{1}$, and \\ Al'bina Gabdullina' \\ ${ }^{1}$ National Research Tomsk Polytechnic University, 634050 Tomsk, Russia
}

\begin{abstract}
As a result, study equation has been obtained which determine the flue gas moisture capacity at the outlet of the condensation heat recovery unit with an error of less than $1 \%$. It possible to at the temperature of the flue gas below the dew point and the known air-fuel ratio efficient. The equation can be used to calculate plants operating on products of gas combustion without Use of tables and programs for calculating the water-vapor saturation pressure.
\end{abstract}

\section{Introduction}

The ways to increase gas turbine unit's efficiency are an application of the condensation heat recovery unit (CHE) [1-5]. The condensation heat recovery unit is applied in regions with low air temperature, where air can be used to cool flue gas more efficiency [6]. If the CHE is applied in installations operating on the Rankine Organic Cycle [7-9], the efficiency will be increased due to using the outlet of flue gas. At the same time, by decrease the flue gas temperature and application the heat of condensation of moisture from them, increase of the boiler efficiency can by $10-15 \%$. The most effective is application of CHE in gas burning units because condensed water liberated from flue gas almost does not contain harmful substances except dissolved $\mathrm{CO}_{2}$ and $\mathrm{O}_{2}$, which can be easily deaerated. Therefore, the condensate can be useful for both the installation itself and for other purposes.

\section{Moisture capacity calculation at the input and output of the CHE}

To determine the flue gas moisture content at the input and output of the installation is necessary for calculating CHE. Considering that moisture content determination by calculation is very time-consuming, Seminuk's equations are used for estimative computation of natural gas combustion [8]. It is assumed that at the entrance to the CHE, water vapor in gases has a temperature above the dew point, and at the outlet it is lower. The moisture content is determined in $\mathrm{kg}$ or $\mathrm{g}$ of moisture ratiu to $1 \mathrm{~kg}$ of dry gases.

The moisture content at entrance to the CHE was calculated from the equation

\footnotetext{
Corresponding author : gal@tpu.ru
} 


$$
d_{\mathrm{n}}=\left(0.13-\mathrm{d}_{\mathrm{nv}} \alpha_{\mathrm{yx}}\right) /\left(\alpha_{\mathrm{fg}}-0.058\right),
$$

where $\alpha_{\mathrm{fg}}$ is the air-fuel ratio in the flue gas; $\mathrm{d}_{\mathrm{nv}}$ - the air moisture content before burning, $\mathrm{kg} / \mathrm{kg}(\mathrm{cg})$.

The moisture content at flue gas to the CHE when it is cooled below the dew point was calculated from the equation

$$
d_{\mathrm{fg}}=\mathrm{P}_{\mathrm{wv}} /\left(P_{\mathrm{g}}-P_{\mathrm{wv}}\right) \mathrm{R}_{\mathrm{dg}} / \mathrm{R}_{\mathrm{wv}}
$$

where $P_{\mathrm{g}}$ static pressure in the gas boiler pass, $\mathrm{P}_{\mathrm{wv}}$ - water vapor saturation partial pressure in $\mathrm{Pa}$, is determined by tables [11] on the temperature of flue gas behind the $\mathrm{CHE}\left(\mathrm{t}_{\mathrm{fg}}\right) ; \mathrm{R}_{\mathrm{dg}}$ $/ \mathrm{R}_{\mathrm{wv}}$ is the ratio of the gas constant of dry gases to the gas constant of water vapor, for natural gas depending on $\alpha_{\mathrm{fg}}$ was calculated from the equation [8]

$$
\mathrm{R}_{\mathrm{dg}} / \mathrm{R}_{\mathrm{wv}}=\left(0.09924+0.622 \alpha_{\mathrm{fg}}\right) /\left(0.199+\alpha_{\mathrm{fg}}\right) .
$$

The values of $R_{d g} / R_{w v}$ are given in Table 1 .

Table 1. Dependence of the ratio $\mathrm{R}_{\mathrm{dg}} / \mathrm{R}_{\mathrm{wv}}$ to a $\alpha_{\mathrm{fg}}$.

\begin{tabular}{|c|c|c|c|c|c|c|c|}
\hline$\alpha_{\mathrm{fg}}$ & 1 & 1.5 & 2 & 2.5 & 3 & 3.5 & 4 \\
\hline $\mathrm{R}_{\mathrm{dg}} / \mathrm{R}_{\mathrm{wv}}$ & 0.6015 & 0.6076 & 0.6108 & 0.6129 & 0.6143 & 0.6154 & 0.6162 \\
\hline
\end{tabular}

In table 2 are presented the calculations of $\mathrm{d}_{\mathrm{fg}}$ according to equation (2) as a function of $\alpha_{\mathrm{fg}}$ and $\mathrm{t}_{\mathrm{fg}}$ at $\mathrm{P}_{\mathrm{g}}=100000 \mathrm{~Pa}$.

Table 2. $\mathrm{d}_{\mathrm{fg}}$ value, $\mathrm{g} / \mathrm{kg}(\mathrm{dry})$ was calculated from the equation (2).

\begin{tabular}{|c|c|c|c|c|c|c|c|c|}
\hline \multicolumn{2}{|c|}{ Parameters } & \multicolumn{7}{|c|}{$\alpha_{\mathrm{fg}}$} \\
\cline { 2 - 9 } & 1 & 1.5 & 2 & 2.5 & 3 & 3.5 & 4 \\
\hline \multirow{4}{*}{$t_{\mathrm{fg}}, \circ$} & 10 & 7.48 & 7.55 & 7.60 & 7.62 & 7.64 & 7.65 & 7.66 \\
\cline { 2 - 9 } $\mathrm{C}$ & 20 & 14.41 & 14.55 & 14.63 & 14.68 & 14.71 & 14.74 & 14.76 \\
\cline { 2 - 9 } & 30 & 26.68 & 26.95 & 27.09 & 27.18 & 27.25 & 27.29 & 27.33 \\
\cline { 2 - 9 } & 40 & 47.96 & 48.44 & 48.70 & 48.87 & 48.98 & 49.06 & 49.13 \\
\cline { 2 - 9 } & 50 & 84.77 & 85.62 & 86.08 & 86.37 & 86.57 & 86.72 & 86.83 \\
\cline { 2 - 9 } & 60 & 149.87 & 151.38 & 152.19 & 152.71 & 153.06 & 153.32 & 153.52 \\
\hline
\end{tabular}

These equations are derived on the basis of reduced fuel characteristic.

Seminuk [8] has suggested equation for moisture content calculation that does not require saturated vapor pressure determination and is widely-used in scientific literature, $\mathrm{kg} / \mathrm{kg}($ dry)

$$
d_{\mathrm{fg}}=\left(0.0006382+0.004 \alpha_{\mathrm{fg}}\right) /\left(0.199+\alpha_{\mathrm{fg}}\right) \operatorname{EXP}\left(0.062 t_{\mathrm{fg}}\right) .
$$

\begin{tabular}{|c|c|c|c|c|c|c|c|c|}
\hline \multirow{2}{*}{\multicolumn{2}{|c|}{ Parameters }} & \multicolumn{7}{|c|}{$\alpha_{\mathrm{fg}}$} \\
\hline & & 1 & 1.5 & 2 & 2.5 & 3 & 3.5 & 4 \\
\hline \multirow{6}{*}{$\begin{array}{c}t_{\mathrm{fg}},{ }^{\circ} \\
\mathrm{C}\end{array}$} & 10 & 7.19 & 7.26 & 7.30 & 7.33 & 7.34 & 7.36 & 7.37 \\
\hline & 20 & 13.37 & 13.50 & 13.57 & 13.62 & 13.65 & 13.68 & 13.69 \\
\hline & 30 & 24.85 & 25.10 & 25.23 & 25.32 & 25.38 & 25.42 & 25.45 \\
\hline & 40 & 46.19 & 46.66 & 46.91 & 47.07 & 47.18 & 47.26 & 47.32 \\
\hline & 50 & 85.87 & 86.73 & 87.20 & 87.49 & 87.70 & 87.84 & 87.96 \\
\hline & 60 & 159.63 & 161.23 & 162.10 & 162.65 & 163.02 & 163.30 & 163.51 \\
\hline
\end{tabular}

Table 3 shows the results $d_{\mathrm{fg}}$ in $\mathrm{g} / \mathrm{kg}(\mathrm{sg})$ are presented by the equation (4), and table 4 the ratio error are presented by equation (4) with ratio to (2).

Table 3. $\mathrm{d}_{\mathrm{fg}}$ value, was calculated from the equation (3). 
Table 4. Ratio error value was calculated from the equation (3) ratio to (2), \%.

\begin{tabular}{|c|c|c|c|c|c|c|c|c|}
\hline \multirow{2}{*}{\multicolumn{2}{|c|}{ Parameters }} & \multicolumn{7}{|c|}{$\alpha_{f g}$} \\
\hline & & 1 & 1.5 & 2 & 2.5 & 3 & 3.5 & 4 \\
\hline \multirow{6}{*}{$\begin{array}{c}t_{\mathrm{fg}},{ }^{\circ} \\
\mathrm{C}\end{array}$} & 10 & 3.86 & 3.86 & 3.86 & 3.86 & 3.86 & 3.86 & 3.86 \\
\hline & 20 & 7.22 & 7.22 & 7.22 & 7.22 & 7.22 & 7.22 & 7.22 \\
\hline & 30 & 6.85 & 6.85 & 6.85 & 6.85 & 6.85 & 6.85 & 6.85 \\
\hline & 40 & 3.69 & 3.69 & 3.69 & 3.69 & 3.69 & 3.69 & 3.69 \\
\hline & 50 & -1.30 & -1.30 & -1.30 & -1.30 & -1.30 & -1.30 & -1.30 \\
\hline & 60 & -6.51 & -6.51 & -6.51 & -6.51 & -6.51 & -6.51 & -6.51 \\
\hline
\end{tabular}

Table 4 shows that the ratio error calculation by equation (4) for most points more than $6-7 \%$, so in this research, based on multidimensional approximation of the according table. 2 was receive the equation

$$
d_{\mathrm{fg}}=\left(4.287+0.0321 \alpha_{\mathrm{fg}}\right) \operatorname{EXP}\left(0.0597 t_{\mathrm{fg}}\right) .
$$

Percentage error of computation using equation (5) relative to data in table 2 does not exceed 5\%. However, obvious trend is observed between the difference of calculation according to equations (5) and (2) depending on $\mathrm{t}_{\mathrm{fg}}$. This trend was approximated by the third degree polynominal with determination coefficient of 0.9992 . The result the equation was obtained.

$$
d_{\mathrm{fg}}=\left(4.287+0.0321 \alpha_{\mathrm{fg}}\right) \operatorname{EXP}\left(0.0597 t_{\mathrm{fg}}\right)+\left(0.7068-0.208 t_{\mathrm{fg}}+0.01254 t_{\mathrm{fg}}{ }^{2}-0.000175 t_{\mathrm{fg}}{ }^{3}\right)(6)
$$

Table 5 show the calculations of $\mathrm{d}_{\mathrm{fg}}$ by equation (6), and in table. 6 - ratio error of calculation according to equation (6) ratio to (2). The error for all points does not exceed $1 \%$. in calculation by equation (6).

\begin{tabular}{|c|c|c|c|c|c|c|c|c|}
\hline \multirow{2}{*}{\multicolumn{2}{|c|}{ Parameters }} & \multicolumn{7}{|c|}{$\alpha_{\mathrm{fg}}$} \\
\hline & & 1 & 1.5 & 2 & 2.5 & 3 & 3.5 & 4 \\
\hline \multirow{6}{*}{$\begin{array}{c}t_{\mathrm{fg}},{ }^{\circ} \\
\mathrm{C}\end{array}$} & 10 & 7.55 & 7.58 & 7.61 & 7.64 & 7.67 & 7.70 & 7.73 \\
\hline & 20 & 14.42 & 14.47 & 14.52 & 14.58 & 14.63 & 14.68 & 14.73 \\
\hline & 30 & 26.92 & 27.02 & 27.12 & 27.21 & 27.31 & 27.40 & 27.50 \\
\hline & 40 & 48.29 & 48.47 & 48.64 & 48.82 & 48.99 & 49.17 & 49.34 \\
\hline & 50 & 85.24 & 85.56 & 85.88 & 86.19 & 86.51 & 86.83 & 87.15 \\
\hline & 60 & 150.82 & 151.40 & 151.98 & 152.55 & 153.13 & 153.71 & 154.28 \\
\hline
\end{tabular}

Table 5. $\mathrm{d}_{\mathrm{fg}}$ the value in $\mathrm{g} / \mathrm{kg}$ (dry) to (6).

Table 6. Ratio error of calculation by (6) and (2), \%.

\begin{tabular}{|c|c|c|c|c|c|c|c|c|}
\hline \multicolumn{2}{|c|}{ Parameters } & \multicolumn{9}{c|}{$\alpha_{\mathrm{fg}}$} & \multicolumn{2}{c|}{} \\
\cline { 3 - 9 } & & 1 & 1.5 & 2 & 2.5 & 3 & 3.5 & 4 \\
\hline \multirow{4}{*}{$t_{\text {fg }}}$, & 10 & -0.97 & -0.35 & -0.20 & -0.24 & -0.39 & -0.60 & -0.85 \\
\cline { 2 - 9 } & 20 & -0.06 & 0.57 & 0.74 & 0.71 & 0.58 & 0.39 & 0.16 \\
\cline { 2 - 9 } & 30 & -0.92 & -0.27 & -0.09 & -0.11 & -0.23 & -0.41 & -0.63 \\
\cline { 2 - 9 } & 40 & -0.69 & -0.05 & 0.13 & 0.10 & -0.02 & -0.21 & -0.44 \\
\cline { 2 - 9 } & 50 & -0.56 & 0.07 & 0.23 & 0.20 & 0.07 & -0.13 & -0.37 \\
\cline { 2 - 9 } & 60 & -0.63 & -0.02 & 0.14 & 0.10 & -0.04 & -0.25 & -0.50 \\
\hline
\end{tabular}

\section{Conclusion}

As a result, study equation has been obtained which determine the flue gas moisture capacity at the outlet of the condensation heat recovery unit with an error of less than $1 \%$. It possible to at the temperature of the flue gas below the dew point and the known air-fuel ratio efficient. 
The equation can be used to calculate plants operating on products of gas combustion without Use of tables and programs for calculating the water-vapor saturation pressure.

\section{References}

1. A.A. Kudinov, Increase in the efficiency of the surface-type condensation heat. Industrial energy, 6, 49 (2002)

2. A.A. Abramovskikh, U.A. Ulyanova, S.V. Lavrinenko, A,A. Matveeva, D. Malishev, MATEC Web Conf. 91, 01002 (2017)

3. K. Larionov, D. Gvozdjakov, A. Zenkov, Z. Zaytsev, MATEC Web Conf. 110, 01034 (2016)

4. D. Hazell, Modeling and Optimization of Condensing Heat Exchangers for Cooling Boiler Flue Gas (Ph.D. Dissertation, Lehigh University, 2011).

5. N. Galashov, S. Tsibulskiy, A. Kiselev, MATEC Web Conf. 72, 01029 (2016)

6. N. Galashov, S. Tsibulskii, A. Matveev, V. Masjuk, EPJ Web Conf. 110, 01019 (2016)

7. N. Galashov, S. Tsibulskiy, T. Serova, EPJ Web Conf. 110, 01068 (2016)

8. L.G. Semenyuk, Industrial energy, 8, 47 (1987)

9. Ya.L. Pekker, Energy (1977)

10. A.A. Alexandrov, B.A. Grigoriev, MPEI (1999)

11. E. Lemmon, M. Huber, M. McLinden, REFPROP, standard reference database 23, version 8.0, National Institute of Standard and Technology, (2007) 